\title{
AÇÃO AFIRMATIVA NO BRASIL: MULTICULTURALISMO OU JUSTIÇA SOCIAL?*
}

\author{
João Feres Júnior \\ Professor do Instituto de Estudos Sociais e Políticos da UERJ e coordenador do Grupo de \\ Estudos Multidisciplinares da Ação Afirmativa (GEMAA). E-mail: <jferes@iesp.uerj.br> \\ Luiz Augusto Campos \\ Professor do Instituto de Estudos Sociais e Políticos da UERJ e vice-coordenador do Grupo de \\ Estudos Multidisciplinares da Ação Afirmativa (GEMAA).E-mail: <lascampos@gmail.com>
}

http://dx.doi.org/10.1590/ 0102-6445257-293/99

O idealismo é um dos maiores vícios intelectuais da humanidade, presente em várias disciplinas acadêmicas e no debate público de diversos países e culturas. Sua incapacidade de reconhecer a mediação é particularmente perniciosa quando o assunto é a política, atividade prática que se desenrola exatamente no intercâmbio entre as ideias e o mundo da experiência. Assim, ao formularmos a questão que guia o presente ensaio, "Podemos considerar as ações afirmativas políticas multiculturalistas?”, precisamos imediatamente entender que ela não pode ser respondida no abstrato. Isto é, até pode, mas tal resposta será de exíguo valor. Primeiro, temos o problema de que a definição de Ação Afirmativa (AA) é muito ampla, englobando uma variedade de políticas de desenhos e parâmetros diversos, muito dependentes de contextos institucionais e culturais de cada país onde essa política foi implantada. Por conseguinte, as justificações públicas possíveis para sua implantação também variam: umas

Agradecemos aos pareceristas anônimos de Lua Nova pelos comentários e sugestões muito pertinentes. 
podem ser multiculturalistas, mas outras puramente concernentes ao âmbito da justiça social. Segundo, e isso é mais importante no que toca à crítica do idealismo, as justificações em uma sociedade democrática não existem no vácuo, ou em um mundo ideal da deliberação democrática. Pelo contrário, na realidade, justificações sempre ocorrem em contextos discursivos que são institucionalmente formatados. Cada um desses contextos é caracterizado por suas próprias normas e estruturas de deliberação e justificação. Todas são políticas no sentido de abrigarem o embate entre diferentes projetos, interesses, valores e noções acerca da vida coletiva. Portanto, a resposta correta para a pergunta que nos colocamos tem de ser buscada em cada um desses contextos de deliberação, ou pelo menos nos mais relevantes.

A questão então deve ser reformulada da seguinte maneira: podemos considerar as ações afirmativas raciais 258 adotadas no Brasil a partir de 2003 políticas multiculturalistas? A resposta que apresentamos a seguir é construída a partir da análise das justificações da ação afirmativa racial nos principais contextos discursivos institucionais em que ela foi tema em nosso país. O intuito é sempre testar se as justificações usadas podem ser ditas de natureza multiculturalista ou se elas pertencem a outras famílias de argumentos morais. Trata-se dos contextos que conferiram à ação afirmativa racial existência, legalidade e legitimidade.

O plano de trabalho é o seguinte: primeiro faremos um rápido preâmbulo sobre a narrativa nacional das relações raciais no Brasil contra a qual a justificação da ação afirmativa racial deve ser colocada: a chamada democracia racial. Para levarmos a sério as questões que a teoria do multiculturalismo coloca, é preciso termos primeiro uma boa noção do conteúdo da cultura societal que estamos 
estudando $^{1}$. Segundo, analisamos a Constituição de 1998, particularmente suas passagens que conferem direitos especiais a minorias étnicas e culturais. Sabe-se de antemão que não há previsão de políticas de ação afirmativa na Carta, pelo menos da maneira como vieram a ser adotadas posteriormente no país. Mas, como veremos, há sim elementos que propiciam interpretações complexas dos direitos das minorias e grupos discriminados. Terceiro, partimos para o exame de discursos do ex-Presidente Fernando Henrique Cardoso sobre racismo e desigualdade racial no Brasil, e sobre medidas para combatê-los. A escolha de Cardoso se justifica por ter sido ele o primeiro presidente do Brasil a reconhecer publicamente a existência desses problemas no país. Quarto, analisaremos as justificações das políticas de ação afirmativa racial focando em dois casos paradigmáticos: a UERJ e a UnB. Enquanto as normas do programa de ação afirmativa da universidade carioca explicitam argumentos pertencentes à retórica da justiça social, o programa da UnB é desenhado de maneira a reconhecer uma especificidade cultural do negro. Veremos, contudo, que tanto nesses dois programas quanto no conjunto das políticas de ação afirmativa criadas no Brasil, entre 2003 e 2012, o peso de cada um dos argumentos de justificação, justiça social ou reconhecimento cultural, é muito desigual. Quinto, em busca de medir o peso dessas justificações no debate público, partiremos para uma rápida análise dos argumentos favoráveis à ação afirmativa usados em textos publicados em grandes jornais no período de 2002 a 2009, quando se deu o grosso do debate sobre o tema. Finalmente, nos debruçaremos sobre a decisão do

\footnotetext{
1 O termo societal culture é usado por Will Kymlicka em praticamente toda a sua obra acerca da teoria e prática do multiculturalismo. Nas palavras do autor, "O mundo moderno é dividido naquilo que eu chamarei de culturas societais, cujas práticas e instituições abrangem todas as atividades humanas, tanto na esfera pública quanto privada. Essas culturas societais são tipicamente associadas a grupos nacionais".
} 
Supremo Tribunal Federal (STF) acerca da ação afirmativa racial de 2012, para identificar o peso que argumentos de justiça social e de reconhecimento cultural tiveram naquela situação.

\section{Democracia racial e nação}

Desde os anos 1930, as elites políticas e intelectuais brasileiras investiram em um imaginário nacionalista calcado no elogio à miscigenação. Todavia, essa concepção de brasilidade, assim como a adesão da sociedade como um todo a ela, esteve exposta à contestação intelectual e política de intensidade variável no decorrer de nossa história desde então. A formulação canônica desse imaginário nacional, que leva o nome de "democracia racial", é frequentemente atribuída à Casa-Grande $\mathcal{E}^{\circ}$ senzala, livro seminal de Gilberto Freyre, a despeito da expressão de fato não aparecer no volumoso tratado². Mais do que 260 radicalmente original, Freyre parece ter capturado o Zeitgeist em que elites e intelectuais brasileiros já estavam ressignificando a miscigenação, até então deplorada pelas teorias do determinismo racial.

Como em alguns outros países de passado colonial, México e Colômbia, por exemplo, no Brasil a nacionalidade foi simbolicamente construída por narrativas culturais que valorizam os elementos não brancos e não europeus da população. Constituídas depois de conquistada a independência política das metrópoles europeias no século XIX, tais narrativas tiveram o papel de fundar simbolicamente novas nações. No caso do Brasil, elas serviram de contraponto às teorias do discurso do determinismo racial, que lançavam sobre a população majo-

\footnotetext{
2 David Lehmann destaca que a expressão só aparece em algumas traduções para o inglês dos textos de Freyre. Ainda assim, ela é utilizada antes para falar da suposta tendência do país em se tornar uma democracia racial do que como um termo descritor da realidade existente no presente.
} 
ritariamente não branca um futuro sombrio. De origem europeia, essas teorias foram recebidas pela intelectualidade brasileira e serviram como base ideológica para o aparecimento de projetos eugenistas e sanitaristas no país, que tinham por objetivo a contenção e o controle do elemento não branco, supostamente pernicioso à nossa formação nacional.

A democracia racial surgiu então como um projeto novo de nação, capaz de superar o pessimismo lançado pelo determinismo racial e, ao mesmo tempo, permitir, exatamente por meio da miscigenação, a sobrevivência do ideal de branqueamento e a manutenção de hierarquias raciais, como inúmeros críticos não cansam de apontar. Fato é que a democracia racial rapidamente transformou-se na ideologia nacional por excelência, promovida pela propaganda do Estado Novo de Getúlio Vargas, uma ditadura que reprimia as expressões culturais dos grupos étnicos que compunham o país, entre eles italianos, alemães, sírio-libaneses, japoneses, poloneses, espanhóis etc. Exemplarmente, o governo estadonovista proibiu o ensino e o uso de línguas estrangeiras, assim como associações de base étnica e manifestações culturais "exóticas" ao país. Foi na esteira desse processo de criação cultural da nacionalidade, capitaneado pelo Estado, que o samba tornou-se o ritmo nacional, o carnaval, particularmente na sua versão carioca, a festa símbolo do Brasil, e a mulata seu personagem mais paradigmático.

A ideologia nacional fundada no mito da democracia racial sobreviveu à queda do Estado Novo, tornando-se verdadeiramente hegemônica no país, a despeito de críticas advindas de setores da intelectualidade negra. Ela atravessou o período democrático pré-1964 sem sofrer grandes ameaças e foi muito bem recebida pela ditadura militar que se instalou a partir daquele ano. Não era intenção dos mandantes fardados criar motivos para a 
mobilização política do povo e para a intensificação de demandas e tensões sociais, como mostra o episódio da entrevista concedida por Angela Gilliam ao Pasquim, no auge da repressão ${ }^{3}$.

Contudo, o processo de democratização experimentado pela sociedade brasileira a partir do final da década de 1970 contribuiu para colocar em questão essa narrativa nacional, ou cultura societal hegemônica, para utilizar um conceito adotado por Kymlicka. A pluralização das vozes e do sistema partidário, trazendo um novo impulso participativo e o ressurgimento dos movimentos sociais no espaço público, começaram a forjar uma nova concepção de país, que foi em parte capturada, qual um instantâneo, pela Constituição Federal de 1988, também chamada de "Constituição Cidadã”. Seria a nova Constituição baseada em uma nova narrativa de nação?

Como já foi dito, não pretendemos responder a essa 262 questão no plano abstrato, mas sim mostrar que concepções de nação e de sociedade brasileira, articuladas à questão racial, foram adotadas no plano concreto das instituições, particularmente aquelas que regulam as políticas de ação afirmativa. Comecemos pela Constituição, pois ela é um referencial normativo para as demais instituições.

\footnotetext{
3 Em 1973, a antropóloga e intelectual pública negra norte-americana Angela Gilliam deu entrevista ao jornal O Pasquim, na qual afirmou haver racismo no Brasil. O general Juarez Paz Pinto, encarregado da censura do jornal, liberou a publicação da entrevista, mas isso enfureceu seus superiores que ameaçaram abortar a publicação e acabaram por transferir a censura do jornal para Brasília. O trecho que acompanhou a entrevista, de autoria do próprio Jaguar, editor do jornal e entrevistador, revelou o grau de penetração da ideologia da democracia racial mesmo na cultura da esquerda do Brasil daquela época, isso para não citar o alto grau de machismo: "Uma mulata tamanho família e dois crioulos entraram na redação e vieram direto para minha mesa. Eu queria dar uma entrevista pro Pasquim. Olhei pra ela e fiquei pensando várias coisas, que a mulata era muito boa, que não convinha dizer que ela era muito boa na frente dos crioulos (ainda mais porque todos portavam ameaçadores cabelos black power (blequepau), qual seria a escola de samba dela, e outros pensamentos chauvinistas do mesmo jaez (Epa)!”.
} 


\section{“Constituição Cidadã" e multiculturalismo}

Interessa-nos aqui colocar a seguinte pergunta: é correto entender a nova Constituição como multiculturalista? A resposta a essa questão não é simples. Gisele Cittadino (1999) aponta para o caráter comunitarista do documento, ressaltando seu aspecto progressista, que inclui, para além das proteções amplas dos direitos civis liberais, a centralidade dos direitos políticos de participação e o imperativo da atividade estatal na promoção de direitos sociais ${ }^{4}$. Mas o viés comunitarista identificado por ela não se desdobra em uma dimensão multiculturalista, ainda que possamos argumentar que o comunitarismo que a autora identifica no processo constitucional brasileiro, caracterizado pela abertura das instituições à sociedade civil, é do tipo mais propício ao desenvolvimento de futuros acordos multiculturais.

De fato, nossa Constituição parece conter algumas disposições que apontam naquela direção, particularmente pelo que dispõem os artigos 215 e 216, onde destacamos:

Art. 215. O Estado garantirá a todos o pleno exercício dos direitos culturais e acesso às fontes da cultura nacional, e apoiará e incentivará a valorização e a difusão das manifestações culturais.

$\S 1^{\circ}$ - O Estado protegerá as manifestações das culturas populares, indígenas e afro-brasileiras, e das de outros grupos participantes do processo civilizatório nacional. $\S 2^{\circ}$ - A lei disporá sobre a fixação de datas comemorativas de alta significação para os diferentes segmentos étnicos nacionais.

\footnotetext{
4 Nas palavras de Cittadino (1999, p. 73): "Pretendeu-se [...] conformar um Estado de bem-estar social, nos moldes europeus, através da previsão constitucional [...] de um amplo sistema de direitos constitucionais, mecanismos jurídicos relativos ao controle de omissões do poder público e uma atuação política do Poder Judiciário. Implementar justiça distributiva, em resumo, é o objetivo fundamental do constitucionalismo ‘comunitário' brasileiro”.
} 
$\S 3^{\circ}$ - A lei estabelecerá o Plano Nacional de Cultura, de duração plurianual, visando ao desenvolvimento cultural do País e à integração das ações do poder público que conduzem à: (I) defesa e valorização do patrimônio cultural brasileiro; (II) produção, promoção e difusão de bens culturais; (III) formação de pessoal qualificado para a gestão da cultura em suas múltiplas dimensões; (IV) democratização do acesso aos bens de cultura; (V) valorização da diversidade étnica e regional. (Incluído pela Emenda Constitucional $n^{\circ} 48$, de 2005).

$\mathrm{O}$ artigo 216, em seguida, define o que seria o "patrimônio cultural" da nação:

Art. 216. Constituem patrimônio cultural brasileiro os bens de natureza material e imaterial, tomados individualmente ou em conjunto, portadores de referência à identidade, à ação, à memória dos diferentes grupos formadores da sociedade brasileira, nos quais se incluem: I - as formas de expressão; II - os modos de criar, fazer e viver; III - as criações científicas, artísticas e tecnológicas; IV - as obras, objetos, documentos, edificações e demais espaços destinados às manifestações artístico-culturais; $\mathrm{V}$ - os conjuntos urbanos e sítios de valor histórico, paisagístico, artístico, arqueológico, paleontológico, ecológico e científico.

Uma leitura rápida desses artigos sugere resposta decididamente positiva à questão que abre esta seção: a Constituição brasileira tem um caráter multiculturalista. Mas tal resposta nos parece insuficiente, pois outras interpretações do texto constitucional são possíveis.

O caput do artigo 215 anuncia o dever do Estado de proteger e promover "direitos culturais" e "manifestações culturais". E no artigo 216 fica estabelecido que essa proteção e promoção deve se dar pelo provimento de meios 
simbólicos e materiais. Porém, uma leitura atenta do caput do artigo 215 sugere a subordinação desses direitos e manifestações a uma concepção de "cultura nacional". No parágrafo $1^{\circ}$ do mesmo artigo isso se torna ainda mais claro, pois o texto nomeia explicitamente as culturas populares (leia-se autóctones), indígenas e afro-brasileiras e indica que tal nomeação se deve ao fato de elas serem "participantes do processo civilizatório nacional”. O texto deixa uma abertura para a inclusão de "outros grupos" nessa categoria de "participantes", mas de fato só as duas acima são explicitamente identificadas. No artigo 216, a expressão utilizada é um pouco diferente: "grupos formadores da sociedade brasileira”, mas o significado é praticamente o mesmo.

É seguro dizer que expressões como "processo civilizatório nacional" e "formadores da sociedade brasileira" reverberam as pretensões hegemônicas da cultura societal associada à ideia de democracia racial. Elas têm um forte sentido comunitarista, de um povo que é consciente da sua própria identidade. Mas elas podem ser lidas também em um sentido multiculturalista. Isto se entendermos que o artigo constitucional captura, como um instantâneo fotográfico, um momento histórico no qual negros e indígenas encontram-se em franco processo de reconhecimento por parte das instituições nacionais, com o adendo de ainda haver uma abertura no texto para a incorporação de grupos que porventura no futuro venham a reclamar seu papel de "formadores" ou "participantes" da cultura societal. Essa interpretação corrobora a tese do próprio Kymlicka (2001) de que o multiculturalismo é produto de uma evolução a partir das primeiras formulações do comunitarismo, monoculturais e fechadas. Mas há uma tensão, ou mesmo um paradoxo, nessa interpretação, que diz respeito à formação da cultura societal brasileira. Tal paradoxo na verdade está inscrito na própria Carta, pois a mesma comunidade que se abre à participação dos grupos marginalizados no processo 
civilizatório se define de modo a ressaltar o mito das três raças, fundamental na ideologia da democracia racial.

A Constituição nomeia indígenas e afro-brasileiros explicitamente. Os brancos europeus não são nomeados, algo que aponta para sua posição como enunciadores do próprio texto. Isto é, a Constituição pode ser lida como um acordo que os brancos oferecem aos "outros" da nação. Sem ser explicitamente enunciada, é sua voz que "fala" o documento. O ponto é que as coisas faladas misturam reconhecimento da diferença e conformidade ao mito da democracia racial. Como já notado por outros autores, o próprio mito encerra esse paradoxo: valoriza os elementos não europeus ao mesmo tempo que os submete hierarquicamente aos brancos; incorpora à narrativa da nação mirando o embranquecimento. Não há resolução fácil para esse problema, como veremos adiante.

Ainda sobre a questão da avaliação do caráter hipote266 ticamente multiculturalista de nossa Constituição, devemos levar em conta que, como assevera o próprio Kymlicka (2001), o processo de cidadanização dos grupos discriminados não se esgota na proteção de suas práticas culturais, é necessário também promover sua inclusão política e econômica $^{5}$. Conteria a Carta de 1988 dispositivos para esse efeito?

A resposta parece ser afirmativa no que toca aos indígenas, particularmente se considerarmos que a Constituição de 1988 dedica todo o Capítulo VIII a esse grupo, prevendo várias medidas que visam à preservação de seu modo de vida, conforme dispõe, em especial, o artigo 231:

São reconhecidos aos índios sua organização social, costumes, línguas, crenças e tradições, e os direitos

\footnotetext{
5 O termo cidadanização é emprestado por Kymlicka de James Tully, que, por seu turno, o define como a disposição de negociar como iguais os termos de pertencimento com o objetivo de alcançar-se um consenso, ou seja, algo que vá além da extensão formal de direitos legais a minorias.
} 
originários sobre as terras que tradicionalmente ocupam, competindo à União demarcá-las, proteger e fazer respeitar todos os seus bens.

Se essas disposições, uma vez cumpridas, garantiriam sua plena cidadanização, isso é algo que precisa ser avaliado na prática, e há sinais evidentes de que não são suficientes para tal. Contudo, não é nosso objetivo tratar em detalhe do caso indígena no presente ensaio. Ele é muito interessante, complexo e política e humanitariamente urgente no Brasil. Faremos isso em oportunidade futura. Nossa presente reflexão tem por objeto o segundo grupo nomeado na Carta, os afro-brasileiros que, dependendo da maneira como são contados, variam de $7,6 \%$ a $50,7 \%$ da população nacional ${ }^{6}$.

Como vimos, apesar de a Constituição também reconhecer os afro-brasileiros como um dos grupos "participantes do processo civilizatório nacional”, cujas manifestações culturais devem ser preservadas e promovidas pelo Estado, o tratamento dispensado a esse segmento é bastante diferente. Com exceção das referências contidas no artigo 68 e no parágrafo $5^{\circ}$ do artigo 216 dos Atos das Disposições Constitucionais Transitórias (ADCT), não há qualquer dispositivo voltado à proteção das práticas culturais ou promoção de inclusão política e econômica dos afro-brasileiros ou negros e negras, a não ser para os quilombolas, ou seja, àqueles que se identificam como membros de comunidades remanescentes de antigos quilombos. As passagens da carta onde isso acontece vão abaixo, respectivamente:

\footnotetext{
6 Se consideramos negros somente as pessoas que se identificam como pretos no Censo do IBGE de 2010, a proporção deles na população nacional é de 7,6\%. Se chamarmos de negros ao agregado de pretos e pardos $(43,1 \%)$, como o fazem alguns autores, esse número salta para 50,7\%. Dados disponíveis em: <http:/ /www. ibge.gov.br/home/estatistica/populacao/censo2010/caracteristicas_da_populacao/tabelas_pdf/tab3.pdf $>$.
} 
Art. 68. Aos remanescentes das comunidades dos quilombos que estejam ocupando suas terras é reconhecida a propriedade definitiva, devendo o Estado emitir-lhes os títulos respectivos.

Art. 216.

$\S 5^{\circ}$ - Ficam tombados todos os documentos e os sítios detentores de reminiscências históricas dos antigos quilombos.

Aqui se nota um aspecto interessante da Constituição. Ambos, indígenas e quilombolas, são tratados como minorias étnicas, culturalizadas, por assim dizer. Ou seja, eles são representados no texto como comunidades dentro da comunidade nacional. Esse dado corrobora a interpretação de que o documento contém de fato elementos multiculturalistas, isto é, de um comunitarismo aberto às demandas da dife268 rença cultural. Mas o que dizer do imenso contingente de pretos e pardos que, a despeito de não pertencerem a uma comunidade quilombola ou não adotarem religião e costumes afro-brasileiros, são ainda vítimas históricas de discriminação racial no Brasil; têm suas oportunidades de acesso a bens materiais, simbólicos e culturais reduzidas devido ao preconceito e ao racismo que permeiam nossas relações sociais, e, consequentemente, não têm acesso pleno à cidadania? A Carta reserva aos não brancos os mesmos direitos e garantias franqueados aos demais cidadãos brancos, mas será que esse acordo é suficiente para promover a efetiva cidadanização dessa parcela imensa da população brasileira?

Seria no mínimo ingênuo supormos que a Constituição em si é fonte exclusiva do "acordo" político e social que organiza a sociedade brasileira. Mais correto é tomar toda a evolução normativa e institucional ocorrida a partir da Constituição, ela incluída, ao longo do recente processo de democratização de nosso país. E no tocante ao caso exami- 
nado nesse ensaio, é inegável que as políticas de ação afirmativa para negros (ou pretos e pardos) foram um importante desenvolvimento para a inclusão simbólica e material desse grupo na sociedade brasileira. Criadas primeiramente por meio de leis estaduais ou de decisões dos conselhos das universidades a partir de 2003, as ações afirmativas finalmente viraram Lei federal em $2012^{7}$, mesmo ano em que sua constitucionalidade foi ratificada pelo STF por unanimidade.

Vale a pena, então, reformular a questão, da seguinte maneira: consideradas a Constituição, as leis e as instituições públicas que tratam da questão racial no Brasil, pode-se afirmar sua natureza multiculturalista? Até agora examinamos o conteúdo das normas constitucionais e chegamos à conclusão de que a Carta é um documento complexo, que possui tons multiculturalistas, mas abarca também concepções comunitaristas mais excludentes, ainda vinculadas ao mito da democracia racial. Ademais, também mostramos que a Constituição não estabelece normas para a cidadanização plena de pretos e pardos. Nas seções seguintes, veremos se as políticas de ação afirmativa contribuem para tal cidadanização, tentando ao mesmo tempo responder se elas, da maneira como existem no Brasil, podem ser consideradas políticas multiculturalistas.

A primeira etapa de nossa análise mostra que, a despeito de elementos multiculturalistas presentes na justificação de direitos especiais de minorias historicamente discriminadas na Constituição, tal justificação não pode ser facilmente estendida à maioria não branca da população brasileira, isto é, aos pretos e pardos.

\section{A ação afirmativa no discurso da presidência}

Vários fatores contribuíram para o advento e a disseminação da ação afirmativa racial no Brasil. Os estudos sobre desi-

7 Trata-se da chamada "Lei de Cotas", Lei n ${ }^{\circ} 12.711$ (Brasil, 2012). 
gualdades raciais, produzidos nas décadas de 1970, 1980 e 1990, os primeiros a usarem dados estatísticos nacionais, forneceram base acadêmica para a denúncia do racismo brasileiro, historicamente encampada pelo Movimento Negro. Este último, por seu turno, adotou uma postura política mais propositiva e articulada com o Estado e com agências internacionais. Tal confluência entre os diagnósticos da academia e da sociedade civil se combinou com uma mudança, ainda que vacilante, de postura do governo Fernando Henrique Cardoso em relação à questão racial no país.

Mala Htun tem razão quando diz que a introdução de ações afirmativas raciais no país se valeu de uma confluência de pressões vindas das agências internacionais, da academia, do movimento negro e do próprio governo. Por outro lado, a autora exagera ao afirmar que a combinação de fatores reflete o "abandono por parte do Estado brasileiro da tese da democracia racial”. Se grande parte do movimen270 to negro e dos estudiosos das desigualdades raciais faziam críticas mais veementes ao mito da democracia racial, o governo federal nunca rechaçou explicitamente tal ideário nacional. Ademais, como mostramos anteriormente, nem a própria Constituição Federal está isenta de ecos dessa ideologia, exatamente nas disposições que tratam dos direitos multiculturalistas. Em suma, a tese de Htun nos parece por demais apressada e simplificadora.

A relação ambivalente do governo federal com o mito da democracia racial fica evidente na posição do governo Fernando Henrique Cardoso sobre as ações afirmativas raciais. Em 1996, o Ministério da Justiça organizou o seminário internacional Multiculturalismo e racismo: o papel da ação afirmativa nos Estados democráticos contemporâneos justamente como o objetivo de congregar acadêmicos e membros da sociedade civil para discutir o tema. No discurso de abertura, Cardoso começou elogiando as ambivalências nacionais, qualificando a nação como 
"cheia de contrastes e de desigualdades de todo tipo, mas também de diferenças - que não são só desigualdades de raça, de cor, de cultura".

O então presidente recorreu aos seus estudos sobre o racismo em Florianópolis para ressalvar que tal ambivalência não anula o preconceito existente no Brasil, mas em seguida destacou que "não devemos, entretanto, exagerar nessa crítica e nessa autocrítica", pois se as ambivalências da nossa formação social revelam "de um lado, a hipocrisia, há, de outro, a abertura”. Ou seja, na visão de Cardoso, ainda que a discriminação seja um dos traços de nossa sociedade, isso não quer dizer que ela seja o elemento que a define. Isso o leva a concluir que seria perigoso importar de forma mecânica soluções para os nossos problemas de outra realidade nacional (leia-se, ações afirmativas raciais), pois "as aves que aqui gorjeiam, não gorjeiam como lá”, o que significa que a discriminação e o preconceito que aqui temos não são iguais aos de outras formações culturais".

Qualquer semelhança desse discurso com o "equilíbrio de antagonismos" da obra de Freyre está longe de ser coincidência. A crítica inicial que o então presidente faz às visões edulcoradas das relações raciais brasileiras dá lugar, na maior parte de seu discurso, a um elogio da concepção de identidade nacional híbrida, contraditória, singular e, por isso, positiva, muito próxima daquela delineada por Freyre na década de 1930. Segundo essa concepção, não deveríamos adotar aqui políticas que foram criadas para resolver o problema da discriminação racial alhures:

Devemos, pois, buscar soluções que não sejam pura e simplesmente a repetição ou a cópia de soluções imaginadas para situações em que também há discriminação e preconceito em um contexto diferente do nosso. É melhor, portanto, buscarmos uma solução mais imaginativa. 
Conectando esse trecho ao nome e à intenção básica do seminário, fica evidente que Cardoso reconhecia a necessidade de políticas para diminuir as desigualdades raciais, mas, ao mesmo tempo, era relutante quanto à implantação aqui do modelo estadunidense de ação afirmativa racial.

Foi, portanto, surpreendente a aprovação dada por Cardoso à adoção de ações afirmativas raciais durante a Conferência de Durban, em 2001. Mesmo para a delegação brasileira, tal aprovação pareceu "um raio em céu azul", para usar a expressão de Marx, citada por Edna Roland, militante negra e relatora geral da Conferência. Entretanto, é preciso destacar que a mudança de rumo do governo federal não foi tão diametral quanto possa parecer.

Ao fim de seu governo, Fernando Henrique Cardoso lançou o Programa Nacional de Ações Afirmativas, porém, não implantou uma só cota racial em universidades. Mesmo as políticas pensadas para aumentar a diversidade dos seus minis-

272 térios não saíram do papel e, em alguns casos, como no Itamaraty, se baseavam na distribuição de bolsas e não em reservas de vagas. Mas a despeito da timidez do governo em implantar ações afirmativas raciais efetivas e amplas, é importante notar que ele sempre esteve longe de defendê-las como políticas de promoção da diversidade étnico-cultural. Nos termos do então presidente, tais medidas visam basicamente a "criar condições para que todos os brasileiros se beneficiem da igualdade de oportunidades sem qualquer discriminação”.

\section{Políticas de ação afirmativa e suas justificações}

Como vimos até aqui, a Constituição Federal, a despeito de alguns elementos multiculturais, não tratou da cidadanização da população não branca sob a ótica do reconhecimento da diferença. O governo Fernando Henrique Cardoso não apenas resistiu ao discurso multiculturalista de defesa da ação afirmativa racial, como também adotou uma atitude vacilante em relação à modalidade mais usual desse gênero 
de política pública: a cota racial. Na verdade, a primeira experiência com essa modalidade de política partiu do Estado do Rio de Janeiro, que aprovou, em 2001, uma lei que previa reserva de vagas para negros no vestibular das suas universidades estaduais (Estado do Rio de Janeiro, 2001).

Durante todo o processo de formulação e implantação das cotas raciais fluminenses, houve uma oscilação entre uma retórica multiculturalista de elogio às diferenças e uma retórica redistributivista. Ao justificar a adoção de cotas raciais, o Projeto de Lei $n^{\circ}$ 2.490/2001, aprovado pela Assembleia Legislativa do Estado do Rio de Janeiro (ALERJ), lembra que grande parte dos "negros e pardos brasileiros" é "vítima de discriminação e, sobretudo por questões econômicas, não consegue acesso ao ensino de qualidade, fator crucial para possibilitar a ascensão econômica e profissional desses cidadãos". Diante dessa situação, seria necessário "implantar programas educacionais, que respeitem diferenças e contribuam para a promoção da igualdade social". Usando os termos de Gerd Baumann, a justificativa do projeto de lei se caracteriza por uma fusão da lógica dos direitos comunitários com a lógica dos direitos individuais, já que mescla uma retórica calcada na "igualdade social" e "questões econômicas" com outra que menciona o "respeito às diferenças".

As alterações introduzidas posteriormente, em 2003, na Lei estadual $\mathrm{n}^{\circ} 4.151$, tornam evidentes as tensões entre essas duas retóricas ou justificações. A redação original do projeto havia gerado dois problemas. Primeiro porque reservava vagas no vestibular para "negros e pardos". Note-se que o termo "negro" é tradicionalmente empregado pelo movimento negro e por alguns estudiosos das relações raciais brasileiros para se referirem aos pretos e pardos, registrados nas pesquisas realizadas pelo IBGE. Logo, ao falar em "negros e pardos", o projeto de lei nem adotava a categorização do movimento negro, nem tampouco a do 
IBGE. Foi só depois de um encontro entre militantes negros e gestores da Universidade do Estado do Rio de Janeiro (UERJ) com o Secretário de Ciência e Tecnologia do Estado do Rio de Janeiro, que o termo "pardo" foi suprimido.

Contudo, se a supressão do termo "pardo" parece ter refletido o fortalecimento de um projeto multiculturalista para as cotas, ao identificar o beneficiário com a categoria "negro", propugnada pelo Movimento Negro, outras mudanças reforçaram o caráter redistributivista. $\mathrm{O}$ primeiro projeto reservava $40 \%$ das vagas para cotas raciais mais $50 \%$ para estudantes oriundos de escolas públicas, perfazendo uma cota total de $90 \%$ de vagas reservadas. O novo projeto encaminhado pela então Governadora Rosinha Matheus não somente restringia essas cotas a $20 \%$ para negros e $20 \%$ para candidatos oriundos de escola pública, como definia ambos os grupos como "estudantes carentes". Na prática, isso significava que negros e estudantes oriundos de escolas públicas só poderiam 274 se candidatar às vagas reservadas caso pertencessem a famílias de baixa renda. Como reconhece Lilia Tavolaro:

De fato, no contexto da política de cota na UERJ, onde a categoria "carente" foi institucionalizada como o critério principal dos beneficiários das cotas, os discursos sobre e em prol da raça acabaram conectando a negritude diretamente à condição socioeconomicamente desfavorável dos candidatos. Consequentemente, mesmo quando vista de uma perspectiva assertiva em termos raciais [race-assertive], a "experiência negra" foi sempre amalgamada à experiência do excluído socioeconomicamente.

Embora o discurso de elogio às diferenças e reconhecimento da negritude tenha estado presente desde os primeiros dias das cotas raciais adotadas no Rio de Janeiro, pode-se dizer que ele sempre apareceu mesclado a outro discurso eminentemente redistributivista. Assim, é no 
mínimo apressado afirmar que "a implementação de cotas raciais na UERJ pode ser entendida como parte de um novo projeto racial [para o Brasil] que começa a mudar a interpretação e os usos das categorias raciais a partir dos anos 1970". Em vez de se opor frontalmente ao "projeto racial" calcado na mistura racial, a lei de cotas adotada no Rio de Janeiro se vale desse discurso apenas em parte. Mais do que o "fortalecimento da consciência negra", as cotas da UERJ parecem desde sempre mais comprometidas em matizar as desigualdades socioeconômicas entre brancos e negros.

Quanto à relação com um discurso multiculturalista, é possível dizer que o sistema de cotas raciais adotado pela Universidade de Brasília (UnB) em 2004 foi um antípoda do modelo implantado nas universidades estaduais do Rio de Janeiro. Ainda assim, existem alguns elementos do programa de cotas da UnB que a distanciam do discurso de elogio das diferenças em si.

O modelo adotado pela UnB, assim como o fluminense, estabelece reserva de $20 \%$ das vagas de cada curso de graduação para candidato "negros". No entanto, as nuances que diferenciam os programas são fundamentais para entender os sentidos distintos de seus procedimentos. Ao contrário das cotas do Rio de Janeiro, a autodeclaração racial não foi considerada suficiente para que um estudante se candidate às cotas na UnB. No manual do processo de seleção dessa universidade, constava que "o candidato deve ser preto ou pardo", "se declarar como negro" e, além disso, se submeter a uma "comissão de verificação racial", incumbida de determinar a identidade racial dos beneficiários potenciais, basicamente através de entrevistas e da avaliação de suas fotos.

A exigência de que o candidato seja "preto ou pardo", além disso, se declare "negro", mostra como o programa da UnB está mais estreitamente relacionado a um processo de politização da negritude. Ser negro não é visto como um dado de fato, mas como uma identidade política a ser assu- 
mida pelas vítimas potenciais de preconceito: os pretos e pardos. Tal perspectiva reflete, em grande medida, a história das cotas da UnB, aprovadas depois de um caso de racismo na universidade e da articulação entre professores e o movimento de alunos negros da instituição, chamado Enegrescer. Não é gratuito, aliás, que a comissão de verificação racial adotada seja composta por membros do Movimento Negro, além de professores, alunos e cientistas sociais.

Tudo isso leva a crer que o modelo de cotas da UnB está mais afinado com uma perspectiva multiculturalista que defende a politização da negritude para além da mera redistribuição de recursos entre grupos raciais. O programa dessa universidade tem por objetivo prover reconhecimento a um grupo culturalmente demarcado e dotado de autoconsciência. Não basta que o potencial beneficiário declare ter os traços fenotípicos que tradicionalmente são objeto de preconceito racial no Brasil, aquele que Oracy Nogueira 276 (1998) chamou de preconceito de marca. Vale acrescentar que, ao contrário da UERJ e da UENF (Universidade Estadual do Norte Fluminense), a UnB não adotou inicialmente cotas para estudantes carentes ou de escolas públicas.

No entanto, embora o modelo inicialmente adotado pela UnB tenha sido mais simpático à politização da negritude, ele também possui elementos que destoam de uma teoria política multiculturalista. $\mathrm{O}$ primeiro deles se refere à transitoriedade das cotas raciais. Segundo resolução do Conselho Universitário da UnB, as cotas devem ser avaliadas a cada dez anos com o intuito de se determinar a sua manutenção ou não. Note-se que tal resolução está em acordo com a recomendação da Organização das Nações Unidas em relação ao tema. Ao mesmo tempo que a ONU reconhece que "o princípio da equidade às vezes requer que os Estados adotem ações afirmativas", ela acrescenta que "tal ação pode envolver a concessão de algum tratamento diferencial por um tempo para parte da população interessada". Como 
percebe Kymlicka (1995), mais do que uma nuance marginal, a transitoriedade de uma dada ação afirmativa subverte o sentido multicultural que tal política pode assumir:

Muitos liberais, particularmente na esquerda, abriram uma exceção no caso de ações afirmativas para grupos raciais em desvantagem. Mas em um sentido essa é uma exceção que confirma a regra. A ação afirmativa é geralmente defendida como uma medida temporária necessária para levar-nos mais rapidamente na direção de uma sociedade cega às diferenças de cor [color-blind]. Ela é planejada para remediar anos de discriminação, e por meio disso levar-nos mais perto de uma espécie de sociedade que teria existido se tivéssemos respeitado a separação entre Estado e etnicidade desde o início. Desse modo, a Convenção da ONU sobre Discriminação Racial endossa programas de ações afirmativas somente onde eles têm esse caráter temporário e corretivo. Longe de abandonar o ideal de separação entre Estado e etnicidade, tal ação afirmativa é um modo de tentar atingir esse ideal.

Não estamos propondo aqui que essa simples regra procedimental seja suficiente para esvaziar a ação afirmativa racial adotada pela UnB de seu caráter multiculturalista. Nosso objetivo é somente destacar as ambivalências presentes nesse programa. Mesmo tendo sido um dos modelos de cotas vigentes no Brasil mais próximo de um ideal multiculturalista, ainda assim o programa da UnB incorpora elementos que o descolam do multiculturalismo.

Se tomarmos o contexto imediatamente anterior à padronização das políticas de ação afirmativa no sistema federal de ensino superior e médio, produto da "Lei de Cotas" (Lei federal $n^{\circ} 12.711 / 2012$ ), notamos que a maior parte das universidades brasileiras adotava ações afirmativas de corte socioeconômico e não racial, a despeito do que a cobertura midiática sugere. Das 70 universidades públicas brasileiras 
com algum tipo de ação afirmativa em 2011, 60 (85\%) adotavam políticas para alunos egressos de escolas públicas e 40 (58\%) medidas para alunos negros, ou pretos e pardos . Por si só, esse dado indica a preponderância de uma concepção redistributivista da ação afirmativa no Brasil por todo o período de quase dez anos desde a criação do primeiro programa à aprovação da Lei federal, em 2012, em contraposição a uma compreensão multiculturalista desse tipo de política.

Mesmo entre as 40 instituições que adotavam ações afirmativas para negros, 36 tomavam como critério de corte a renda e/ou a proveniência da escola pública dos candidatos. Nesses casos, não bastava apenas se declarar negro, preto ou pardo, mas também possuir uma condição de carência social. Ou seja, do total de 70 universidades com ação afirmativa, somente 4 tomavam exclusivamente a identidade étnico-racial do candidato como critério.

Pode-se dizer que essa ascendência de critérios socio278 econômicos sobre critérios estritamente raciais ou étnicos foi reforçada pela "Lei de Cotas", que normatizou as cotas de todas as universidades federais brasileiras a partir de sua publicação, em 2012. Isso porque a legislação subsumiu a reserva de vagas para pretos, pardos e indígenas à cota para estudantes oriundos de escolas públicas e economicamente carentes. Conforme indica a Figura 1, as vagas de cada curso em uma universidade ou instituto federal devem ser distribuídas obedecendo uma ordem hierárquica de reservas. Do total de vagas oferecidas em um curso, $50 \%$ devem ser destinadas a estudantes que cursaram o ensino médio integralmente em escolas públicas. Dessas vagas, metade delas devem ser reservadas para estudantes carentes, isto é, cuja renda per capita familiar seja igual ou inferior a 1,5 salário mínimo. As cotas para pretos, pardos e indígenas se aplicam somente aos grupos oriundos de escolas públicas e devem ser proporcionais à representatividade desse grupo no estado em que se situa a instituição de ensino. 
Figura 1

Distribuição de reservas de vagas nas universidades e institutos federais

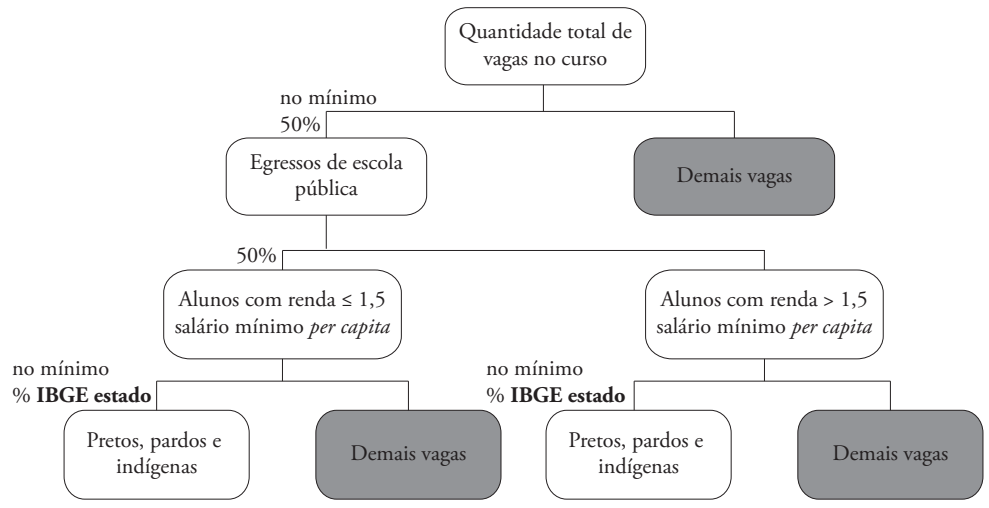

Fonte: elaboração dos autores.

Nesse sistema, é impossível que algum candidato se beneficie de uma cota somente pelo fato de ele ser preto, pardo ou indígena, pois é necessário ainda comprovar, no mínimo, ter cursado o ensino médio em escolas públicas. Além disso, o percentual final reservado aos grupos raciais incidirá somente sobre metade das vagas, evidência de que o critério racial não é o mais relevante para a lei. Tudo isso apenas corrobora a conclusão geral de que as ações afirmativas raciais brasileiras mantiveram uma relação bastante ambivalente, para não dizer distante, de princípios de justiça multiculturalistas.

\section{A controvérsia pública na grande mídia}

Já examinamos as leis (constitucionais e infraconstitucionais), os critérios de aplicação dos programas, o discurso do Executivo, e agora vamos averiguar como o debate público acerca das ações afirmativas raciais tratam a questão do multiculturalismo. Como constatamos, os critérios procedimentais das ações afirmativas adotados pelas universidades públicas brasileiras mostram o papel marginal que ideais multiculturalistas tiveram na sua concepção. Porém, pode ser que tais ideais tenham 
tido um papel mais relevante no debate público acerca dessas políticas, pois neste plano circula um cabedal de justificações geralmente mais amplo do que aqueles esposados pelas instituições. Essa é a hipótese que exploramos a seguir.

Muitos intelectuais interpretaram a introdução de ações afirmativas raciais no país como uma perigosa "opção pela promoção da raça e pelo multiculturalismo" ou uma celebração equivocada das "supostas diferenças étnicas e raciais no multiculturalismo e na diversidade". Em outras oportunidades, apontamos o fato de vários críticos das políticas de ação afirmativa no Brasil as associarem ao multiculturalismo de modo apressado e automático. Nosso objetivo aqui é olhar para o outro lado da contenda e verificar até que ponto a defesa pública das ações afirmativas se inspira em valores e conceitos multiculturalistas ${ }^{8}$.

Para melhor entender as disputas semânticas em torno da ação afirmativa racial que se dão no debate públi280 co, realizamos pesquisa sobre o tratamento dado ao tema pelos dois principais jornais brasileiros, O Globo e Folha de S.Paulo, entre 2001 (ano da entrada do tema no debate midiático) e 2012 (ano em que a cobertura midiática arrefeceu). Dentre editoriais, reportagens, colunas, artigos de opinião, cartas de leitores etc., a pesquisa compilou 1.831 textos. Esse corpus foi analisado por uma equipe de cinco investigadores que, no total, conseguiu identificar 33 argumentos de defesa das ações afirmativas raciais presentes na cobertura da imprensa. A Tabela 1 apresenta tais argumentos, bem como a frequência absoluta e relativa deles dentro do conjunto de textos favoráveis:

\footnotetext{
8 Vale asseverar aqui que mesmo que a política fosse defendida no debate público com argumentos multiculturalistas, isso não a faria mais multiculturalista do que de fato é. E nossa análise já mostrou que concepções multiculturalistas são marginais na elaboração dos programas de ação afirmativa nas universidades públicas, que ostensivamente adotavam critérios de inclusão social e não cultural. Em suma, as acusações de multiculturalismo do campo de oposição às cotas são equivocadas.
} 


\section{Tabela 1}

\section{Justificações favoráveis às Ações Afirmativas Raciais (AAR) no ensino superior}

\begin{tabular}{|c|c|c|c|}
\hline Cód. & Justificação & $f$ & $\%$ \\
\hline f1 & AAR diminui as desigualdades (genérico) & 82 & 20,3 \\
\hline $\mathrm{f2}$ & AAR inclui os excluídos (genérico) & 69 & 17,1 \\
\hline f3 & AAR repara erros cometidos no passado (genérico) & 55 & 13,6 \\
\hline $\mathrm{f4}$ & AAR instaura a igualdade de oportunidades & 46 & 11,4 \\
\hline f5 & $\begin{array}{l}\text { AAR introduz pluralidade nas instituições (empresas, } \\
\text { universidades etc.) }\end{array}$ & 46 & 11,4 \\
\hline f6 & AAR é medida emergencial diante de uma situação crítica & 45 & 11,2 \\
\hline f7 & AAR inclui os beneficiários nos níveis mais altos da sociedade & 37 & 9,2 \\
\hline f8 & AAR combate o racismo/discriminação (genérico) & 32 & 7,9 \\
\hline f9 & AAR teve êxito em outros lugares & 31 & 7,7 \\
\hline $\mathrm{f10}$ & AAR é uma forma de dirimir os efeitos da escravidão no presente & 28 & 6,9 \\
\hline $\mathrm{f11}$ & AAR tem estimulado o debate sobre as desigualdades raciais & 27 & 6,7 \\
\hline $\mathrm{f12}$ & AAR realiza o princípio da igualdade formal de tratamento & 26 & 6,5 \\
\hline f13 & AAR diminui as desigualdades socioeconômicas & 25 & 6,2 \\
\hline $\mathrm{f14}$ & Há sinais de sucesso da AAR no Brasil & 25 & 6,2 \\
\hline $\mathrm{f15}$ & AAR realiza o mérito & 22 & 5,5 \\
\hline $\mathrm{f16}$ & AAR promove a mobilidade social de grupos discriminados & 20 & 5,0 \\
\hline $\mathrm{f17}$ & AAR é uma forma de "indenização" aos que foram escravizados & 19 & 4,7 \\
\hline $\mathrm{f18}$ & AAR combate o racismo/discriminação institucional ou estrutural & 19 & 4,7 \\
\hline $\mathrm{f19}$ & AAR efetiva princípios constitucionais & 17 & 4,2 \\
\hline $\mathrm{f} 20$ & AAR inclui potenciais antes desperdiçados & 15 & 3,7 \\
\hline $\mathrm{f} 21$ & AAR reconhece a diversidade cultural brasileira (genérico) & 13 & 3,2 \\
\hline$f 22$ & AAR reconhece/denuncia o preconceito até então encoberto & 13 & 3,2 \\
\hline$f 23$ & AAR realiza um projeto de nação & 12 & 3,0 \\
\hline $\mathrm{f} 24$ & AAR cria uma classe média negra & 11 & 2,7 \\
\hline $\mathrm{f} 25$ & AAR introduz os beneficiários na cidadania & 11 & 2,7 \\
\hline$f 26$ & AAR consolida/realiza princípios republicanos & 10 & 2,5 \\
\hline$f 27$ & AAR é decisiva para a integração nacional & 7 & 1,7 \\
\hline$f 28$ & AAR capacitará os beneficiários a competir em pé de igualdade & 6 & 1,5 \\
\hline $\mathrm{f} 29$ & AAR dissocia cor de pobreza & 5 & 1,2 \\
\hline $\mathrm{f30}$ & AAR produz prosperidade/eficiência econômica & 5 & 1,2 \\
\hline $\mathrm{f} 31$ & AAR aumentará a autoestima dos beneficiários & 4 & 1,0 \\
\hline $\mathrm{f} 32$ & $\begin{array}{l}\text { AAR combate o racismo/discriminação nas relações sociais } \\
\text { entre indivíduos }\end{array}$ & 4 & 1,0 \\
\hline f33 & $\begin{array}{l}\text { AAR reconhece a contribuição histórico-cultural dos grupos } \\
\text { marginalizados }\end{array}$ & 3 & 0,7 \\
\hline \multirow[t]{2}{*}{$\mathrm{f} 34$} & Outra & 35 & 8,7 \\
\hline & Total & 403 & 100 \\
\hline
\end{tabular}

Fonte: Grupo de Estudos Multidisciplinares da Ação Afirmativa (GEMAA). 
De início, é importante destacar a preponderância de justificações para as ações afirmativas que adotam uma retórica genérica, calcada na crítica às desigualdades (justificação f1) e na inclusão dos excluídos (f2). Vale notar também como o argumento f1 se faz presente em mais de um quinto $(20,3 \%)$ dos textos favoráveis computados. A predominância de uma retórica redistributivista prevalece à medida que descemos na tabela e vemos que os demais argumentos preponderantes destacam como a ação afirmativa instaura a igualdade de oportunidades (f4), inclui os beneficiários nos níveis mais altos da sociedade (f7), tem estimulado o debate sobre as desigualdades raciais (f11), realiza o princípio da igualdade formal de tratamento (f12), diminui as desigualdades socioeconômicas (f13) etc.

Por outro lado, argumentos mais nitidamente ligados a uma retórica multiculturalista só começam a aparecer na parte inferior da tabela, onde se localizam as justificações 282 mais raras na cobertura da imprensa. Afora o argumento que defende a ação afirmativa racial como mecanismo de introdução da pluralidade nas instituições como empresas, universidades etc. (f5), tons multiculturalistas podem ser notados em argumentos como: "a ação afirmativa é instrumento para reconhecer a diversidade cultural brasileira" (f21); "ela é boa por criar uma classe média negra" (f24); e "reconhece a contribuição histórico-cultural dos grupos marginalizados" (f33).

Não estamos aqui sugerindo que a grande mídia é um palco neutro onde o debate público se desenrola. A concentração da propriedade dos meios, sua natureza privada e a falta de regulação pública têm contribuído historicamente para um alto grau de politização e partidarização da mídia nacional, além de sua concentração em um espectro limitado do campo ideológico, que vai do centro à direita. Inúmeros trabalhos ao longo dos anos têm mostrado consistente viés antiesquerda da grande mídia nacional, seja em período eleitoral ou não eleitoral. Esse mesmo viés também se manifesta na cobertura de 
movimentos sociais variados, como o Movimento dos Trabalhadores Rurais Sem-Terra, ou de demandas de igualdade de gênero e, ainda, na cobertura de políticas sociais de governo.

Na verdade, não há paradoxo no comportamento da mídia relatado até aqui. Apesar de os jornais se declararem repetidas vezes contrários às cotas raciais em seus editoriais, eles dão algum espaço aos defensores das cotas, com ênfase para aqueles que adotam argumentos de justiça social, ou seja, redistributivos. A despeito da administração da controvérsia promovida pelo $O$ Globo e a Folha de S.Paulo, a defesa da ação afirmativa racial veiculada pela grande mídia não é muito diferente daquela aqui anteriormente apontada no discurso presidencial, no desenho dos próprios programas e na Lei de Cotas.

A partir de 2009, a quantidade de textos sobre a questão diminuiu sensivelmente nos dois jornais, como mostra o Gráfico 1.

\section{Gráfico 1}

Quantidade de textos sobre Ações Afirmativas Raciais (AAR) publicados nos jornais $O$ Globo e Folha de S.Paulo (2001-2012)

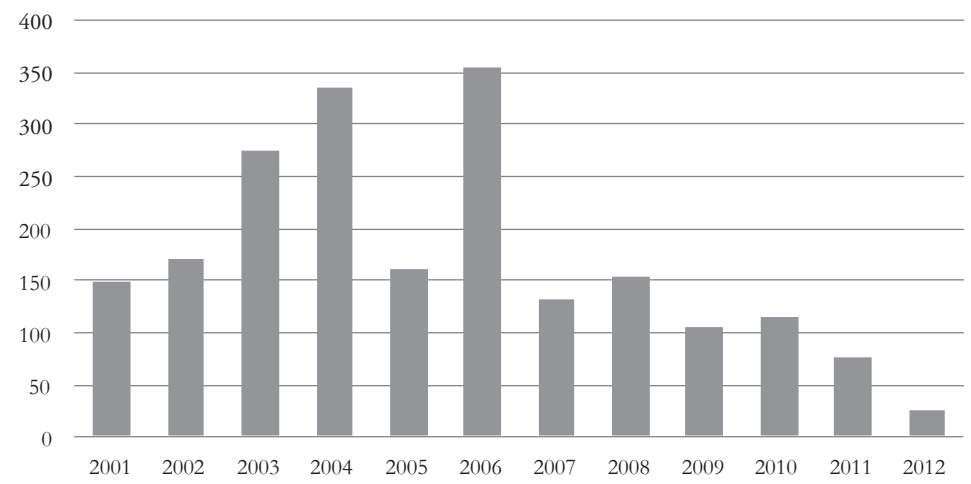

Fonte: Grupo de Estudos Multidisciplinares da Ação Afirmativa (GEMAA).

Naquele mesmo ano foi protocolada, no Supremo Tribunal Federal (STF), uma Ação de Descumprimento de 
Preceito Fundamental (ADPF), que advogava a inconstitucionalidade da política de cotas em vigor na UnB. A coincidência com o arrefecimento da controvérsia midiática sugere que a disputa sobre o sentido político das ações afirmativas raciais pode ter se deslocado para o STF, em cujas mãos estava agora a decisão última sobre a legitimidade, ao menos formal, das políticas afirmativas em vigor no país. Daí a importância de considerar neste ensaio o modo como a Corte se pronunciou quanto à questão.

\section{As cotas no STF}

Em abril de 2012, o plenário do STF se reuniu para julgar a procedência da ADPF 186. Após três dias de julgamento, os ministros decidiram por unanimidade pela improcedência da ação, seguindo o voto do relator, Ministro Ricardo Lewandowski, e considerando, portanto, a política de cotas raciais adotadas pela UnB absolutamente compatível com a Constituição de 284 1988. Contudo, vale notar que alguns argumentos mobilizados por Lewandowski para afirmar a constitucionalidade das cotas da UnB contrariam parte das justificativas usadas pela própria universidade quando da implantação do programa ${ }^{9}$.

Como vimos, o modelo de cotas adotado pela UnB foi o mais próximo de princípios multiculturalistas, tanto nos procedimentos adotados quanto nas intenções manifestadas por seus formuladores. Embora sensível às injustiças produzidas pelas várias formas de discriminação racial existentes no país, o projeto que levou à instituição de cotas na UnB justifica a inclusão de negros na instituição como expediente necessário para formar uma "elite negra capaz de contribuir na formulação de novas políticas públicas que visem a eliminar definitivamente o problema da desigualdade e da exclusão

\footnotetext{
9 No presente ensaio, examinamos somente o voto vencedor do relator. Os votos dos outros ministros, assim como as audiências que foram levadas a cabo quando da instrução do processo, contêm outros argumentos e vozes que fizeram parte desse processo deliberativo, mas que não vamos analisar aqui.
} 
racial no Brasil". Importa destacar quanto tal entendimento é distinto daquele apresentado pelo Ministro Lewandowski em seu voto, particularmente quando afirma que

[...] programas de ação afirmativa tomam como ponto de partida a consciência de raça existente nas sociedades com o escopo final de eliminá-la. Em outras palavras, a finalidade última desses programas é colocar um fim àquilo que foi seu termo inicial, ou seja, o sentimento subjetivo de pertencer a determinada raça ou de sofrer discriminação por integrá-la.

No primeiro caso, as cotas raciais da UnB visam a dar condições para que negros e negras possam formar uma elite autoconsciente de seu pertencimento étnico-racial, e, assim, contribuírem diretamente para solucionar a desigualdade racial no país. No segundo caso, porém, as mesmas cotas são encaradas como medidas que visam justamente a eliminar as distinções raciais no país. É verdade que alguns excertos do voto de Lewandowski se aproximam da justificação fornecida por José Jorge de Carvalho para as cotas da UnB. Isso fica evidente quando o ministro relator argumenta que:

[...] é possível destacar outro resultado importante no que concerne às políticas de ação afirmativa, qual seja: a criação de lideranças dentre esses grupos discriminados, capazes de lutar pela defesa de seus direitos, além de servirem como paradigmas de integração e ascensão social.

Mas embora o trecho supracitado pareça ir ao encontro do projeto da UnB, é preciso notar que, para Lewandowski, a criação de lideranças visa mormente a fornecer padrões de integração social para os membros dos grupos desfavorecidos (no caso, os negros). Isso porque tais programas teriam "como um bônus adicional a aceleração de uma mudança na atitude subjetiva dos integrantes desses grupos, 
aumentando a autoestima que prepara o terreno para a sua progressiva e plena integração social”. Logo, embora o ministro oscile entre uma retórica que elogia a diversidade cultural e outra mais assimilacionista, a capacidade de integração social das ações afirmativas raciais parece sempre suplantar a sua capacidade de reconhecer diferenças.

Evidentemente, isso não quer dizer que a decisão do STF tenha ignorado totalmente a diversidade étnica como um valor. A rigor, tal interpretação seria falsa. Como o voto do relator afirma explicitamente, "justiça social, hoje, mais do que simplesmente redistribuir riquezas criadas pelo esforço coletivo, significa distinguir, reconhecer e incorporar à sociedade mais ampla valores culturais diversificados, muitas vezes considerados inferiores àqueles reputados". Como se vê, a solução encontrada pela decisão do STF é um compromisso entre uma lógica mais forte da justiça social e elementos de direitos multiculturais.

O debate que se seguiu à introdução de ações afirmativas raciais no Brasil viu ressurgir interpretações mais otimistas do imaginário nacionalista pró-mestiçagem, forjado na década 1930. Alguns intelectuais que antes contestavam ou mesmo se opunham ao mito da democracia racial tornaram-se paulatinamente simpáticos a ele quando propostas de ação afirmativa racial começaram a ser aventadas na agenda política ainda na década de 1990. É interessante notar que, nessa campanha pública, esses intelectuais publicistas pintaram a ação afirmativa racial como um espantalho multiculturalista, como simples importação de uma agenda multiculturalista estranha à cultura nacional. O medo de que tal multiculturalismo exótico fosse introduzido no país pelas ações afirmativas raciais fez com que tais intelectuais passassem a destacar mais o potencial normativo e performativo do 
mito da democracia racial do que as incoerências presentes naquele discurso. Mais do que uma simples "mentira", esses autores enfatizam que o mito deve ser encarado como um conjunto de "antecipações e desejos reais das comunidades humanas", o que faz com que a democracia racial "deva ser considerad [a] como um projeto sócio-político interessante", ainda que não totalmente realizado na prática.

No presente ensaio, mostramos que, nos vários âmbitos em que foi debatida e deliberada, a ação afirmativa no Brasil está longe de ser uma política típica do multiculturalismo, ou seja, do reconhecimento da diferença cultural. Há traços aqui e ali de argumentos multiculturalistas na Constituição, no debate público e mesmo na decisão do STF, mas a lógica principal que vigora é a da justiça social, nos termos de um liberalismo igualitário. Respondemos, portanto, à pergunta que nos colocamos no começo do ensaio, que se limitava ao âmbito da faticidade. Resta saber se a ação afirmativa pode ou deve ser uma política de recorte dominantemente multicultural no Brasil. Claro que não há espaço aqui para desenvolver essas respostas em detalhe, mas gostaríamos de arriscar algumas ideias sobre o assunto.

No que toca às minorias indígenas e mesmo aos quilombolas, nos parece óbvio que soluções do tipo multiculturalista devem, sim, ser adotadas. Claro que há uma gradação imensa nos níveis de assimilação dessas minorias, mas essa é uma questão prática que as políticas reais precisam enfrentar. Contudo, para a maioria não branca da nação, a solução multiculturalista, ou, mais especificamente, do reconhecimento da diferença cultural, parece ser parcialmente inadequada. É fato que, em sua teoria do multiculturalismo, Kymlicka identifica grupos cujo objetivo é a integração, mas que precisam de direitos especiais para que essa integração se dê. Pretos e pardos no Brasil se encaixam nessa categoria. Não constituem grupos culturais per se, mas sim grupos discriminados racialmente. Menos do que a proteção ou 
promoção de uma suposta cultura de grupo dos pardos e mesmo da maioria dos pretos, precisamos focar a luta por cidadania na desmontagem de padrões culturais e institucionais racistas que os segregam e discriminam, ou seja, desmontar a branquidade fundamental mas silenciosa de nossas instituições e práticas sociais. A legislação que pune o racismo foi uma solução tentada, mas que obteve êxito limitado até agora. As políticas de ação afirmativa racial nos parecem mais bem equipadas a contribuir para essa mudança, ainda que estejam longe de constituir uma solução definitiva.

Não podemos, entretanto, deixar de lado o fato de que há, ainda que menos centrais para o grosso da população não branca do Brasil, demandas por reconhecimento cultural da cultura negra e afro-brasileira, e que esse tipo de reconhecimento cultural contribui para o trabalho de desmontagem de padrões culturais hegemônicos e excludentes que citamos aqui. As políticas de ação afirmativa racial, 288 desenhadas para a entrada de estudantes no ensino superior, não atendem diretamente a essa demanda. Contudo, não devemos desprezar o potencial que a inclusão de um contingente expressivo de negros e negras no espaço universitário, de onde historicamente estiveram excluídos, tem para a transformação da cultura societal do Brasil.

\section{João Feres Júnior}

é professor do Instituto de Estudos Sociais e Políticos da Universidade Estadual do Rio de Janeiro (Iesp-UERJ) e coordenador do Grupo de Estudos Multidisciplinares da Ação Afirmativa (GEMAA).

\section{Luiz Augusto Campos}

é professor do Instituto de Estudos Sociais e Políticos da Universidade Estadual do Rio de Janeiro (Iesp-UERJ) e vice-coordenador do Grupo de Estudos Multidisciplinares da Ação Afirmativa (GEMAA). 


\section{Bibliografia}

AGASSIZ, L.; AGASSIZ, E. 2000. Viagem ao Brasil:1865-1866. Brasília:

Senado Federal.

ALDÉ, A. 2003. As eleições presidenciais de 2002 nos jornais. ALCEU, v. 3, n. 6, pp. 93-121.

ALDÉ, A.; MENDES, G.; FIGUEIREDO, M. 2007. Tomando partido: imprensa e eleições presidenciais em 2006. Política e Sociedade, n. 10, pp. 153-72.

AMORIM, J. 2001. Projeto de Lei no 2.490/2001. Assembleia Legislativa do Estado do Rio de Janeiro.

AYOUB, A. H. 2007. Mídia e movimentos sociais: a satanização do MST na Folha de S Paulo. Estudos em Jornalismo e Mídia, v. 4, n. 1, pp. 79-93.

BAUMANN, G. 1999. The multicultural riddle: rethinking national, ethnic, and religious identities. New York/London: Taylor \& Francis Group.

BENZAQUEN DE ARAÚJO, R. 1993. Guerra e paz : Casa Grande Ẽ Senzala e a obra de Gilberto Freyre no anos 30. Rio de Janeiro: Editora 34.

BEZERRA, H. D.; MUNDIM, P. S. 2011. Qual foi o papel das variáveis midiáticas na eleição presidencial de 2010?. Opinião Pública, n. 17, pp. 452-76.

BIROLI, F.; MANTOVANI, D. 2010. Disputas, ajustes e acomodações na produção da agenda eleitoral: a cobertura jornalística ao Programa Bolsa Família e as eleições de 2006. Opinião Pública, n. 16, pp. 90-116.

BRASIL. Lei ${ }^{\circ}$ 12.711, de 29 de agosto de 2012. Dispõe sobre o ingresso nas universidades federais e nas instituições federais de ensino técnico de nível médio e dá outras providências. Disponível em: $<$ http:/ / www. planalto.gov.br/ccivil_03/_ato2011-2014/2012/Lei/L12711.htm>. Acesso em: 9 nov. 2016.

CAMPOS, L. A.; FERES JÚNIOR, J. 2014. Ação afirmativa, comunitarismo e multiculturalismo: relações necessárias ou contingentes?. Revista Brasileira de Ciências Sociais, v. 29, n. 84, pp. 103-18.

CAMPOS, L. A.; FERES JÚNIOR, J.; DAFLON, V. T. 2013. Administrando o debate público: $O$ Globo e a controvérsia em torno das cotas raciais. Revista Brasileira de Ciência Política, n. 11, pp. 7-31.

CARDOSO, F. H. 1997a. Abertura do seminário "Multiculturalismo e Racismo”. In: SOUZA, J. (org.). Multiculturalismo e racismo: uma comparação Brasil-Estados Unidos. Brasília: Paralelo 15.

1997b. Pronunciamento do presidente da República na abertura do seminário "Multicultralismo e Racismo". In: SOUZA, J. (org.). Multiculturalismo e racismo: uma comparação Brasil-Estados Unidos. Brasília: Paralelo 15 . 
CARDOSO, F. H.; IANNI, O. 1960. Cor e mobilidade social em Florianópolis: aspectos das relações entre negros e brancos numa comunidade do Brasil meridional. São Paulo: Companhia Editora Nacional (Coleção Brasiliana).

CARVALHO, J. J.; SEGATO, R. L. 2002. Uma proposta de cotas para estudantes negros na Universidade de Brasília. Série Antropologia, UnB, n. 314.

CHOR MAIO, M.; SANTOS, R. V. 2005. Política de cotas raciais, os "olhos da sociedade" e os usos da antropologia: o caso do vestibular da Universidade de Brasília (UnB). Horizontes Antropológicos, v. 11, n. 23, pp. 181-214.

CITTADINO, Gisele. 1999. Pluralismo, direito e justiça distributiva. Rio de Janeiro: Lumen Juris.

DAFLON, V. T.; FERES JÚNIOR, J.; CAMPOS, L. A. 2013. Ações afirmativas raciais no ensino superior público brasileiro: um panorama analítico. Cadernos de Pesquisa, v. 43, n. 148, pp. 302-27.

DAMATTA, R. 1990. Digressão: a fábula das três raças, ou o problema do racismo à brasileira. In: DAMATTA, R. (org.). Relativizando, uma introdução à antropologia social. Rio de Janeiro: Rocco. 1997. Notas sobre o racismo à brasileira. In: SOUZA, J. (org.). Multiculturalismo e racismo: uma comparação Brasil e Estados Unidos. Brasília: Paralelo 15.

ESTADO do Rio de Janeiro. Lei n ${ }^{\circ}$ 3.708, de 9 de novembro de 2001. Institui cota de até $40 \%$ (quarenta por cento) para as populações negra e parda no acesso à Universidade do Estado do Rio de Janeiro e à Universidade Estadual do Norte Fluminense, e dá outras providências. . Lei $n^{\circ} 4.151$, de 4 de setembro de 2003. Institui nova disciplina sobre o sistema de cotas para ingresso nas universidades públicas estaduais e dá outras providências.

FERES JÚNIOR, J.; CAMPOS, L. A. 2013. O discurso freyreano sobre as cotas raciais: origem, difusão e decadência. In: PAIVA, A. R. (org.). Ação afirmativa em questão: Brasil, Estados Unidos, África do Sul e França. Rio de Janeiro: Pallas.

FERES JÚNIOR, J.; CAMPOS, L. A.; DAFLON, V. T. 2011. Fora de quadro: a ação afirmativa nas páginas d'O Globo. Contemporânea - Revista de Sociologia da UFSCar, n. 2, pp. 61-83.

FINAMORE, C. M.; CARVALHO, J. E. C. 2006. Mulheres candidatas: relações entre gênero, mídia e discurso. Estudos Feministas, v. 14, n. 2, pp. 347-62.

FREYRE, G. 2003 [1933]. Casa-grande Ẽ senzala: formação da família brasileira sob o regime de economía patriarcal. 48 ed. São Paulo: Global. 
FRY, P. 1982. Feijoada e "Soul Food": notas sobre a manipulação de símbolos étnicos e nacionais. In: FRY, P. (org.). Para inglês ver: identidade e política na cultura brasileira. Rio de Janeiro: Zahar.

1996. O que a Cinderela Negra tem a dizer sobre política racial no Brasil. Revista da USP, n. 28, pp. 13-34.

2001. Feijoada e Soul Food 20 anos depois. In: FRY, P. (org.). Fazendo antropologia no Brasil. Rio de Janeiro: DP\&A.

GAGNON, A.; TULLY, J. 2001. Multinational democracies. Cambridge/New York: Cambridge University Press.

GILLIAM, A.; GILLIAM, O. 1995. Negociando a subjetividade de mulata no Brasil. Revista Estudos Feministas, v. 3, n. 2, pp. 525-543.

GONÇALVES, E. R. L. 2008. Mídia e movimentos sociais: a representação do MST na revista Isto É. Dissertação de mestrado em Ciências Sociais, Universidade Federal da Bahia, Bahia.

GRIN, M. 2004. Experimentos em ação afirmativa: versão crítica em dois tempos. Econômica, Niterói, v. 6, n. 1, pp. 145-52.

GUIMARÃES, A. S. A. 2007. Desigualdades raciais em novo regime de Estado: as ações afirmativas no governo Lula. In: XXVII Congresso Internacional da LASA. Montréal.

HTUN, M. 2004. From racial democracy to affirmative action: changing State policy on race in Brazil. Latin American Research Review, v. 39, n. 1, pp. $60-89$.

JAGUAR. 1973. Entrevista com Angela Gilliam: O negro continua com a vassoura na mão. O Pasquim, ano 5, n. 6.

KYMLICKA, W. 1995. Multicultural citizenship: a liberal theory of minority rights, Oxford political theory. Oxford, UK/New York: Clarendon Press/ Oxford University Press. 2001. Politics in the vernacular: nationalism, multiculturalism, and citizenship. Oxford, UK/New York: Oxford University Press.

KYMLICKA, W.; NORMAN, W. J. 2000. Citizenship in diverse societies. Oxford, UK ; New York: Oxford University Press.

KYMLICKA, W.; OPALSKI, M. 2001. Can liberal pluralism be exported? Western political theory and ethnic relations in Eastern Europe. New York: Oxford University Press.

LEHMANN, D. 2008. Gilberto Freyre: a reavaliação prossegue. Horizontes Antropológicos, v. 14, n. 29, pp. 369-85.

LEWANDOWSKI, R. 2012. Íntegra do Voto do Relator da Arguição de Descumprimento de Preceito Fundamental 186. Brasília: Supremo Tribunal Federal. Disponível em: <http:/ /www.stf.jus.br/PORTAL/cms/ verNoticiaDetalhe.asp?idConteudo=205890 >. Acesso em: 9 nov. 2016. 
MAGGIE, Y. 1996. Aqueles a quem foi negada a luz do dia: as categorias cor e raça na cultura brasileira. In: CHOR MAIO, M.; SANTOS, R. V. (orgs.). Raça, ciência e sociedade. Rio de Janeiro: Ed. Fiocruz. . 2005. Mário de Andrade ainda vive? O ideário modernista em questão. Revista Brasileira de Ciências Sociais, n. 20, pp. 5-25.

MAGGIE, Y.; FRY, P. 2004. Cotas raciais - construindo um país dividido. Econômica, Niterói, v. 6, n. 1, pp. 153-62.

MAIO, M. C. 1999. O Projeto Unesco e a agenda das ciências sociais no Brasil dos anos 40 e 50. Revista Brasileira de Ciências Sociais, v. 14, n. 41, pp. 141-58.

MATTA, R. 1984. O que faz o brasil, Brasil? Rio de Janeiro: Salamandra.

MIGUEL, L. F.; BIROLI, F. 2009. Mídia e representação política feminina: hipóteses de pesquisa. Opinião Pública, n. 15, pp. 55-81.

MiGUEL, L. F.; COUTINHO, A. A. 2007. A crise e suas fronteiras: oito meses de "mensalão" nos editoriais dos jornais. Opinião Pública, n. 13, pp. $97-123$.

NASCIMENTO, A. et al. 2003. Quilombo: vida, problemas e aspirações do negro. São Paulo: Fundação de Apoio à Universidade de São Paulo/Editora 34.

NOGUEIRA, O. 1998. Preconceito de marca: as relações racias em Itapetininga. São Paulo: Edusp.

O ESTADO de S. Paulo, 13 maio 2002. Agência Estado. FHC cria grupo de trabalho para implementar cota de negros.

PAIXÃO, M. 2013. A lenda da modernidade encantada: por uma crítica ao pensamento social brasileiro sobre relações raciais e projeto de Estado-Nação. Curitiba: Ed. CRV.

PEREIRA, A. M. 2003. Um raio em céu azul: reflexões sobre a política de cotas e a identidade nacional brasileira. Estudos Afro Asiáticos, v. 25, n. 3, pp. 463-82.

PRAVAZ, N. 2003. Brazilian mulatice: performing race, gender, and the nation. Journal of Latin American Anthropology, v. 8, n. 1, pp. 116-46.

RAMOS, A. G. 1955. Patologia social do "branco" brasileiro. Rio de Janeiro: Jornal do Comercio. . 1957. Introdução crítica à sociologia brasileira. Rio de Janeiro: Editorial Andes.

SANTOS, M. A. 2009. Política negra e democracia no Brasil contemporâneo: reflexões sobre os movimentos negros. In: HERINGER, R.; PAULA, M. (orgs.). Caminhos convergentes: Estado e sociedade na superação das desigualdades raciais no Brasil. Rio de Janeiro: Fundação Heinrich Boll/ActionAid. 
SCHWARCZ, L. M. 1993. O espetáculo das raças. Cientistas, instituições e questão racial no Brasil 1870-1930. São Paulo: Companhia das Letras.

SCHWARTZMAN, L. F. 2009. Seeing like citizens: unofficial understandings of official racial categories in a Brazilian university. Journal of Latin American Studies, v. 41, n. 2, pp. 221-50.

SKIDMORE, T. E. 1974. Black into white: race and nationality in Brazilian thought. New York: Oxford University Press.

SOUZA, J. 1997. Multiculturalismo, racismo e democracia: por que comparar EUA e Brasil?. In: SOUZA, J. (org.). Multiculturalismo e racismo: uma comparação Brasil-Estados Unidos. Brasília: Paralelo 15.

STEPAN, N. 1991. "The hour of eugenics": race, gender, and nation in Latin America. Ithaca: Cornell University Press.

TAVOLARO, L. G. M. 2008. Affirmative action in contemporary Brazil: two institutional discourses on race. International Journal of Politics, Culture and Society, n. 19, pp. 145-60.

TODOROV, T. 1993. On human diversity: nationalism, racism, and exoticism in French thought. Cambridge, Mass.: Harvard University Press.

UNITED NATIONS. 1989. General comment n. 18 on International Covenant on Civil and Political Rights. Suíça: Office of the High Commissioner for Human Rights.

VIANNA, H. 1995. O mistério do samba. Rio de Janeiro: Jorge Zahar Editor/ Ed. UFRJ (Coleção Antropologia social).

WADE, P. 1997. Race and ethnicity in Latin America: critical studies on Latin America. Chicago, Ill.: Pluto Press.

WADE, P., URREA GIRALDO, F.; VIVEROS, M.. 2008. Raza, etnicidad y sexualidades: ciudadanía y multiculturalismo en América Latina. Bogotá: Universidad Nacional de Colombia, Facultad de Ciencias Humanas, Instituto CES, Escuela de Estudios de Género (Colección Lecturas CES). 


\section{AÇÃO AFIRMATIVA NO BRASIL: MULTICULTURALISMO OU JUSTIÇA SOCIAL?}

JOÃO FERES JÚNIOR

LUIZ AUGUSTO CAMPOS

Resumo: $\mathrm{O}$ presente artigo pretende responder se as políticas de ação afirmativa racial hoje adotadas no Brasil se encaixam no modelo de políticas multiculturais da maneira como as concebe Will Kymlicka. A questão se justifica para além do interesse teórico, porque elas foram tomadas como uma importação do multiculturalismo anglo-saxão pelos detratores da ação afirmativa. Para tal, emprestamos o conceito de cultura societal, formulado por Kymlicka, e examinamos como a ação afirmativa opera em relação a ele. Em seguida, examinamos os argumentos acerca dessas políticas em vários âmbitos de debate e deliberação (Constituição de 1988, Governo Federal, STF, Programas de Cotas de universidades públicas e jornalismo), para mostrar que a ação afirmativa no Brasil está longe de ser uma política típica do multiculturalismo, ou seja, do reconhecimento da diferença cultural. Há traços aqui e ali de argumentos multiculturalistas na Constituição, no debate público e mesmo na decisão do STF, mas a lógica principal que vigora é a da justiça social, nos termos de um liberalismo igualitário.

Palavras-chave: Ação Afirmativa; Brasil; Multiculturalismo; Will Kymlicka.

\section{AFFIRMATIVE ACTION IN BRAZIL: MULTICULTURALISM OR SOCIAL JUSTICE?}

Abstract: The present contribution examines whether the brand of race-based affirmative action adopted in Brazil can be considered a multicultural policy as defined by Will Kymlicka. Besides its obvious theoretical import, this exploration is also a reply to those that have accused the policies of being an import from Anglo- 
Saxon multiculturalism, and thus inappropriate to Brazil. We will borrow the concept of societal culture from Kymlicka to assess the ways Brazilian affirmative action might interact with it. Then, we will examine the arguments in favor of affirmative action as they were used in the key institutional settings (the Constitution, Federal Government, Supreme Court, affirmative action programs, and the news media) to show that, in Brazil the affirmative action is not chiefly construed as a multicultural policy, that is, as a measure aimed at producing the recognition of cultural difference. There are traces of multiculturalist arguments in the Constitution, in public debate and in some key rulings of the Supreme Court, but the main arguments used to justify the affirmative action pertain to the overall conception of social justice much more akin to egalitarian liberalism.

Keywords: Affirmative Action; Brazil; Multiculturalism; Will Kymlicka.

Recebido: 18/05/2016 Aprovado: 03/11/2016 